\title{
THE GLASGOW COMA SCALE FOLLOWING ACUTE STROKE AND IN-HOSPITAL OUTCOME: AN OBSERVATIONAL STUDY
}

\author{
MD. TITU MIAH ${ }^{1}$, AKM AMINUL HOQUE $^{2}$, RAIHAN ROTAP KHAN ${ }^{3}$, ZANNATUN NUR $^{4}$, MD. SHAHRIAR \\ MAHBUB $^{4}$, RABIUL ISLAM RONY ${ }^{4}$, BINOY KRISHNA TARAFDER ${ }^{5}$, MD. ABU NASERSIDDIQUE ${ }^{1}$
}

\begin{abstract}
:
Acute stroke is a heterogeneous condition and the risk of death can be gauged by various factors. This study sought to evaluate GCS score on admission as a prognostic tool of outcome among stroke patients, by observing the GCS score following acute stroke and in-hospital outcome at a tertiary level hospital in Bangladesh. Stroke is a major health problem in developed countries as well as developing countries like Bangladesh. This observational study was conducted among 122 consecutive patients, fulfilling the WHO stroke defining criteria, from 1st January 2007 to 30th June 2007. Mean age was 59.28 $\pm 14.89(S D)$ years and male female ratio was 2.39: 1 . Cerebral infarct was $49.13 \%$. Intracerebral hemorrhage and subarachnoid hemorrhage was $31.89 \%$ and $18.96 \%$ respectively. Overall in-hospital mortality was $15.57 \%$ though mortality in patients with cerebral infarcts was nil. Patients presenting with GCS between 3 and 8 caused $12.07 \%$ fatality, whereas, none died with GCS score 13-15. Here GCS score showed an inverse relationship with outcome that varied with type of stroke. We can conclude that GCS score on admission might be incorporated as an valuable prognostic parameter in stroke outcome measurement scale.
\end{abstract}

\section{Introduction:}

The Glasgow Coma Scale (GCS) was devised to assess injury severity in a multi-centre study of outcome after severe brain damage. In this scale, three aspects of behaviour are independently measured: motor responsiveness, verbal performance, and eye opening. It is readily understood by a wide range of observers and the overall score allows classification of severity of brain injury for triage and for epidemiological studies. Outcome correlates well with the early GCS both in head injuries and other intensive care patients. It is now used as a tool to predict the outcome in patients admitted for traumatic brain injury, stroke, non-traumatic coma, cardiac arrest, and toxic ingestions. ${ }^{1}$ Determining GCS score of stroke patients at presentation and subsequent follow-up is a routine clinical practice in many institutions.

Physicians are faced with the task of predicting the immediate and long term outcome in stroke patients. It is also important to efficiently and optimally utilize resources. ${ }^{2}$ Acute stroke is a heterogeneous condition and the chances of survival depend on various factors like neurological damage, systemic dysfunction and social factors. Brenn and sheikh observed that the factors associated with adverse outcome in stroke included male sex, unconsciousness, Glasgow coma scale of $<3$, gaze palsy, pupillary changes and incontinence. The risk of death in first few days is best gauged by three clinical variables i.e. coma, paresis and incontinence, the indicators of severity of neurological dysfunction, along with cardiac variables like heart failure, atrial fibrillation and peripheral vascular disease. Patients with none of these factors are more likely to survive. Features suggestive of early brain stem dysfunction are indicators of poor outcome. $^{3}$ Poor GCS on admission $(\mathrm{OR}=12.35)$, deterioration of GCS $(\mathrm{OR}=46.04)$, and haemorrhagic stroke $(\mathrm{OR}=3.45)$ are found to be independent predictors of one-month mortality. ${ }^{4}$ This study sought to evaluate GCS score as a prognostic tool of outcome of stroke patients along with other demographic variables.

1. Assistant Professor, Department of Medicine, Dhaka Medical College, Dhaka.

2. Associate Professor, Department of Medicine, Dhaka Medical College, Dhaka.

3. Indoor Medical Officer, Department of Medicine, Mymensingh Medical College, Mymensingh

4. Post Graduate Trinee, Department of Medicine, Dhaka Medical College \& Hospital, Dhaka.

5. Assistant Registrar, Department of Medicine, Mymensingh Medical College \& Hospital, Mymensingh

Correspondence : Dr. Md. Titu Miah, Assistant Professor, Department of Medicine, Dhaka Medical College, Dhaka E-mail: titu21@yahoo.com 


\section{Methodology:}

This observational study was conducted in department of Medicine, Mymensingh Medical College Hospital, Bangladesh, from 1st January 2007 to 30th June 2007. Study population was consecutively recruited hospitalized stroke patients. Data was collected by standardized structured questionnaire. We defined acute stroke, according to WHO stroke definition. ${ }^{5}$ GCS scoring was recorded at presentation and during subsequent follow ups. Imaging study in the form of CT scan was advised to all patients. Patients having subdural hematoma, brain tumor and brain abscess were excluded from this study. Good outcome was defined as alive patient who had residual disability while poor outcome as death.

\section{Results:}

During the study 122 patients were enrolled. CT scan was not available in 6 patients. GCS was recorded and outcome data were available for all patients. Figure 1 shows the demographic features of the patients. Mean $( \pm \mathrm{SD})$ age was $59.28( \pm 14.89)$ years and male, female ratio was 2.39: 1. Majority of the patients belonged to 60-79 years age group.

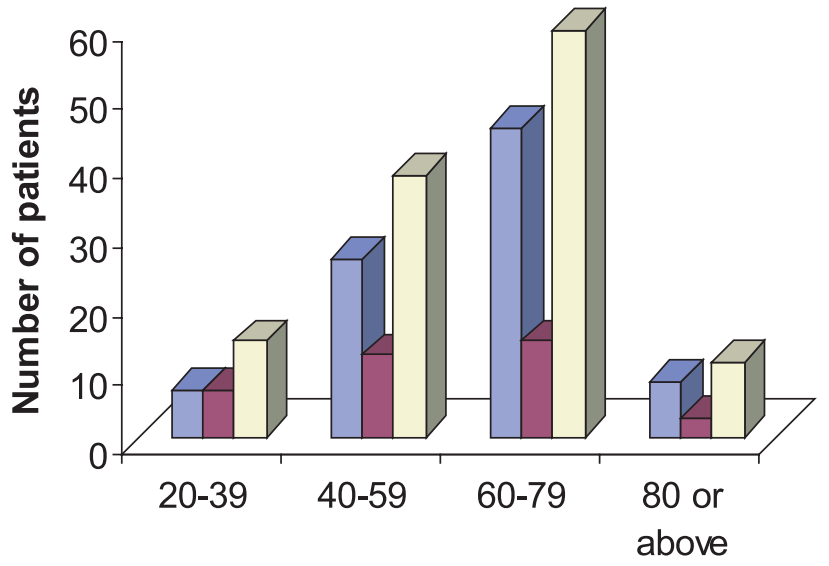

Age range(years)

\section{Male $\square$ Female $\square$ Total}

Fig.-1: Age and sex distribution of the stroke patients $(n=122)$

On imaging, 57 (49.13\%) patients had cerebral infarct, 37 (31.89\%) showed intracerebral hematoma while 22 (18.96\%) showed subarachnoid hemorrhage(Fig.-2). The overall mortality observed was $15.57 \%$.

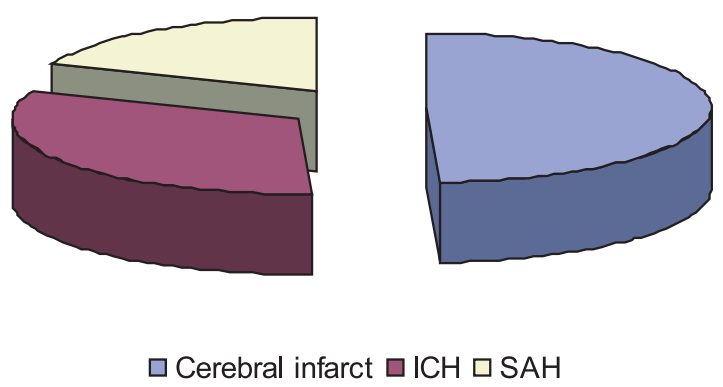

Fig.-2: Sub-types of stroke (according to CT scan findings) $(n=122)$

Figure 3 shows the types of stroke in relation to the outcome of the patients. No patient with cerebral infarct died. Whereas, a total of $9(7.76 \%)$ patients died as a result of intracerebral hematoma and $6(27 \%)$ male patients died from SAH. There is a striking difference between outcome of patient with a cerebral infarct as opposed to patients with hemorrhagic stroke.

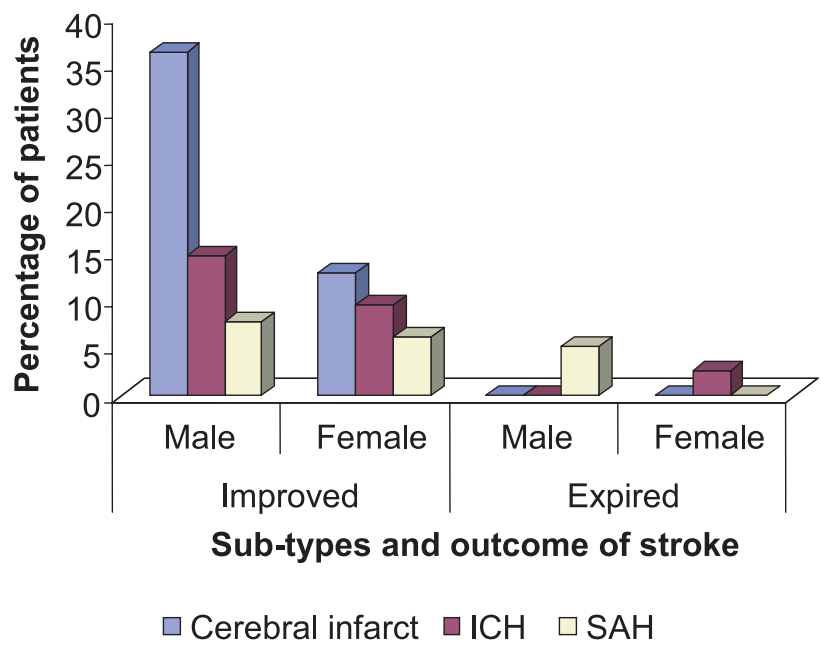

Fig.-3: Sub-types and outcome of stroke $(n=116)$

GCS score showed an inverse relationship with outcome that varied with type of stroke. 25(21.55\%) patients having a cerebral infarct and with a GCS score of $13-15$ showed the best improvement while only $4(3.45 \%)$ patients with an ICH showed good outcome. The scenario is generally poor in case of SAH where only $2(1.72 \%)$ patients with the highest range of GCS score (13-15) demonstrated a good outcome (Fig.-4). 


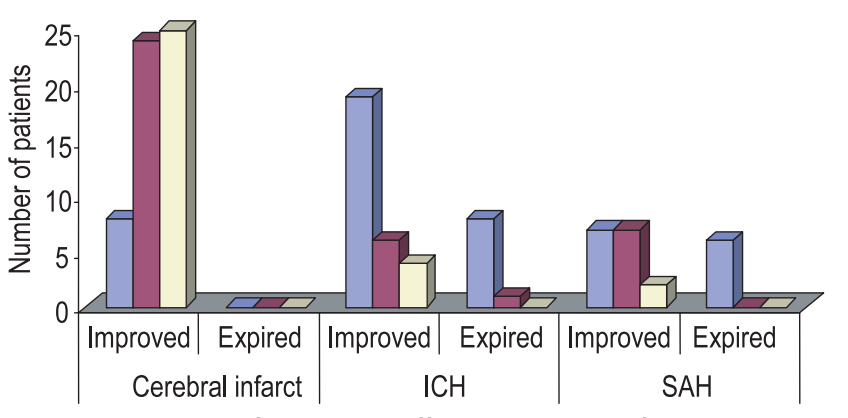

Outcome in different sub-types of stroke

GCS score $\square$ 3-8 $\square$ 9-12 $\square 13-15$

Fig.-4: GCS on admission and outcome in different sub-types of stroke $(n=116)$ :

\section{Discussion:}

Stroke is one of the leading causes of death throughout the world. The burden of stroke is likely to increase substantially in the future because of the aging polution. ${ }^{6}$ In Asia, the problem of stroke has a particularly strong impact, not only because more than half of the world's population live in Asia, but stroke is the predominant vascular disease in many parts of Asia. ${ }^{7}$ The World Health Organization (WHO) estimates that by $2030,80 \%$ of strokes will occur in people living in low and middle income countries, and stroke will account for $7.9 \%$ of all mortality in lowincome countries, coming a close third after ischaemic heart disease and HIV/AIDS. The world wide incidence of stroke has been quoted as 2/1000 population/annum; about 4/1000 in people aged 45-84 years. ${ }^{8,9}$ In Bangladesh population based study about stroke is still not available. A WHO study, in 1990 quoted incidence of mortality due to stroke in India to be $73 / 100,000$ per year. ${ }^{10}$

In order to improve stroke outcome, it is important to identify factors that predict outcome as a first step to apply interventions and any method to predict outcome should be simple, accurate and reproducible. This is even more important in developing countries where management of the condition is still largely conservative and in general wards. ${ }^{11}$ This observational study is thus a relevant one in this regard, as it is one of the few studies in Bangladesh that emphasizes impact of early GCS on outcome.

In this study, mean, age of patients at presentation was 59.28 years with a standard deviation of 14.89 years with an even distribution. Most stroke patients were in between 60-79 years of age and male suffers more $(70.49 \%)$ in comparison to female $(29.50 \%)$ which is consistent with study of Mollah AS, et al. ${ }^{12}$ where mean age was $60 \pm 13.7$ years and highest occurrence of stroke was found in the age group of 61-70 years. These findings are also consistent with mean age (62 years) with Wong $\mathrm{KS}^{6}$ study but differ in respect of male (58\%) patients. This might be a reflection of increasing life expectancy and urbanization.

Among the different subtype of stroke, cerebral infarction was $49.13 \%$, intra cerebral hemorrhage was $31.89 \%$ and subarachnoid hemorrhage found in $18.96 \%$ patients. This results differs with western study where cerebral infarction was $85 \%$, intra cerebral hemorrhage $10 \%$ and subarachnoid hemorrhage $5 \%$ of cases ${ }^{13}$ but a near about similar results was found in study done by Khan MMZA, et al. ${ }^{14}$ This shows the incidence of intra cerebral and sub arachonoid hemorrhage is higher in this study, which might be due to the clinical picture of cerebral infarction is less devastating than intra cerebral hemorrhage which causes decrease frequency of hospitalization among cerebral infarction patients.

The overall mortality rate was $15.57 \%$ which is much lower than the $40 \%$ reported by Ogun et al., ${ }^{15} 34 \%$ reported by Bhalla A et al.2 and $20 \%$ reported by Kazi et al. ${ }^{16}$ In contrary, Heuschmann $\mathrm{PU}^{17}$ et al found overall in hospital death of $4.9 \%$. The patients with hemorrhage had a higher mortality of $7.76 \%$, whereas none died of cerebral infarction. Among the fatal cases only one patient had GCS at presentation $>8$; all others had GCS at presentation in between 38. Also, none of the patients with GCS 13-15 expired. 6 patients did not give us time for CT scan. Among them, 4 expired (GCS below 8 ) and 2 improved with one GCS below $8 \&$ other in between 9-12. Here we find that total GCS below 8 carries a valuable information regarding in-hospital mortality and might be an important prognostic factor of early stroke outcome. Weir, Bradford, and Lees (2002) examined the ability of the GCS to predict 2-week mortality and 3 -month recovery (survival, living at home) in a large cohort of individuals with acute stroke. Their results also suggest that the total GCS score can predict early mortality and 3-month recovery and that the GCS better predicted the outcome of early mortality than the outcome of 3-month recovery. They have demonstrated a strong relationship between the verbal and eye GCS score and outcome of acute stroke 
population. However it is not sufficient to be used as a sole basis for clinical decision making in individual patient. ${ }^{18}$ It would be preferable to combine GCS data in a model with other stroke prognostic factors.

\section{Conclusion:}

Despite the lack of high quality epidemiological data, the burden of stroke seems to be high in

Bangladesh. Although ischaemic strokes are more common than hemorrhagic strokes, the relative proportion of intracerebral haemorrhage and sub arachnoid hemorrhage is higher compared to the western population. Predicting outcome in stroke patients based on GCS score is difficult due to the variability in etiology, presentation and underlying patho-physiology score as well as high quality stroke services is not widely available in Bangladesh. Despite that, GCS can be used as an valuable prognostic tool in acute stroke being a simple scale, specially in countries with poor resources like Bangladesh. There is an urgent need to conduct well-designed epidemiological studies and improve capacity building in order to meet the future challenges.

\section{References}

1. Jennett B. The Glasgow Coma Scale: History and current practice. Trauma 2002;4(2):91-103.

2. Bhalla A, Gupta OP, Gupta SB. Predicting mortality in stroke. Neurology India 2002;50( 3): 279-81

3. Yadav P, Tripathy BK, Agarwal AK. Prognostication in stroke. In : Recent concepts in stroke by Bansal BC (ed). Indian college of Physicians, New Delhi. 1999; 301-309.

4. Ong TZ, Raymond AA. Risk factors for stroke and predictors of one-month mortality.Singapore Med J $2002 ; 43(10): 517-21$

5. Durai PJ, Padma V, Vijaya P, Sylaja PN, Murthy JM. Stroke nd thrombolysis in developing countries. Int J Stroke 2007;2(1):17-26

6. Wong KS. Risk Factors for Early Death in Acute Ischemic Stroke and Intracerebral Hemorrhage: A Prospective Hospital-Based Study in Asia. Stroke. 1999;30:2326-2330.

7. Shi F, Hart RG, Sherman DG, Tegeler CH. Stroke in the People's Republic of China. Stroke. 1989; 20: 1581-1585.
8. Murray CJL, Lopez AD. Alternative projections of mortality and disability by cause 1990-2020: Global burden of disease study. Lancet 1997; 349:14981504 .

9. Mathers CD, Loncar D. Updated projections of global mortality and burden of isease, 2002-2030: data sources, methods and results. Evidence and information for policy working paper. Geneva: World Health Organization. Plos Med 2006; 3:e442

10. Prasad K. Epidemology of cerebrovascular disorders in India. In : Recent concepts in stroke by Bansal BC (ed) Indian college of Physicians, New Delhi. 1999; 4-19

11. Wahab KW, Okubadejo NU, Ojini FI, Danesi MA. Predictors of Short-term Intra-Hospital Case Fatality Following First-ever Acute Ischaemic Stroke in Nigerians Journal of The College of Physicians and Surgeons Pakistan 2008,18 (12): 755-758

12. Mollah AS, Rahman SW, Das KK, Hassanuzzaman M. Mymensingh Med J. 2007; 16(1):20-4.

13. Kasper DL, Braunwald E, Fauci AS, Hauser SL, Longo DL, Jameson JL, et al, editors. Harrison's principles of internal medicine. 16th ed. New Delhi: McGraw-Hill, Medical Publishing Division; 2005. p. 2372-93.

14. Khan MMZA, Arif SM, Parveen S, Bari S, Chowdhury NA, Saha AK et al. Unconscious Patients and Stroke - A Study of 50 cases. J Medicine 2005; 6(1):5-9.

15. Ogun SA, Ojini FI, Ogungbo B, Kolapo KO, Danesi MA. Stroke in South-West Nigeria. A 10-year review. Stroke 2005; 36:1120-2.

16. Kazi R, Jain AP, Gupta OP et al. CSF analysis in stroke patients. MGIMS, Sevagram. (Unpublished data 1990).

17. Heuschmann PU, Kolominsky-Rabas PL, Misselwitz B, Hermanek P, Leffmann C, Janzen et al. Predictors of in-hospital mortality and attributable risks of death after ischemic stroke. Arch Intern Med 2004;164:1761-1768

18. Weir C J, Bradford APJ, Lees KR. The prognostic values of the components of the Glasgow Coma Scale following acute stroke. Q J Med 2003;96:67-74. 